Trakya Eğitim Dergisi

Cilt 9, Sayı 2

Mayıs 2019, 287-301

Geliş Tarihi: 31.10 .2018

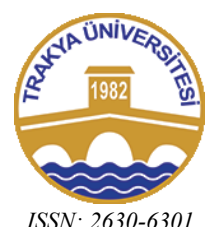

ISSN: 2630-630I
Trakya Journal of Education

Volume 9, Issue 2

May 2019, 287-301

\title{
Çocuk Kitaplarında Yer Alan Hayvan Karakterlerine Çevre Eğitimi Açısından Bakış: İçerik Analizi Çalışması
}

\section{Determination of Animal Characters in Children's Books from the Perspective of Environmental Education: Content Analysis Study}

\author{
Arife PEKER ${ }^{1}$, Berat AHí
}

\begin{abstract}
Öz: Yapılan bu araştırmanın amacı erken çocukluk dönemine yönelik kitaplarda yer alan hayvanların neler olduğunu tespit etmek, karakter özelliklerini anlamak ve bu özelliklerin nasıl yansıtıldığını belirlemektir. Araştırma nitel araştırma modelli olup, veriler içerik analizi tekniğine uygun olarak analiz edilmiştir. Araştırmanın çalışma grubunu belirlemede kriter (ölçüt) örnekleme tekniği kullanılmıştır. Buna göre Türkiye'de kitapları yaygın olan, erken çocukluk dönemine yönelik yayınları çok olan iki yayınevi belirlenmiştir. Yayınevlerinin kitapları belirlenen ölçütlere göre seçilmiştir. Buna göre çalışma grubunda toplam 51 kitap yer almıştır. Çalışma grubunda yer alan kitaplarda 41 farklı türde hayvana değinildiği tespit edilmiştir. Bu hayvanların tamamı iyi karakter rolünde kullanılırken; 10 tanesine aynı zamanda kötü karakter rolü de verilmiştir. Kötü karakter rolüne sahip hayvanlar arasında ayı, kurt, tilki ve kaplan gibi yırtıcı hayvanlar yer almaktadır. Aynı zamanda kitaplarda hayvanların fiziksel ve estetik özellikleri üzerinden de karakter özelliği kurgulandığı tespit edilmiștir. Fiziksel olarak büyük ve güçlü hayvanlar bazı kitaplarda kötü karakter özelliği taşımaktadır. Elde edilen bulgulardan hareketle özellikle kötü karakter özelliği gösteren hayvanlara karşı çocukların olumsuz tutum ve davranış gösterebileceği düşünülmektedir. $\mathrm{Bu}$ nedenle özellikle yayınevlerine ve ailelere, kitapların olay örgüsüne ve hayvanların karakter olarak kullanıldığı kitaplarda karakterlerin yansıtılış şekillerine dikkat etmeleri önerilmektedir.
\end{abstract}

Anahtar sözcükler: Çocuk kitapları, hayvan, erken çocukluk dönemi, çevre eğitimi, içerik analizi

\begin{abstract}
The aim of this research is to determine what animals are involved in early childhood books, to understand their characteristics and to determine how these characteristics are reflected. The research is a qualitative research model and the data are analyzed in accordance with the content analysis technique. The criterion sampling technique was used to determine the study group. According to this book, which is common in Turkey, it is determined early childhood publications for which two publishing houses. The books of the designated publishers were selected according to the determined criteria. Accordingly, a total of 51 books were included in the study group. It was determined that 41 different species of animals were mentioned in the books in the study group. All of these animals were used in the role of good character; 10 were also given the role of bad character. Animals that have the role of bad characters are predators such as bears, wolves, foxes and tigers. At the same time, physical and aesthetic characteristics of animals have been determined. Physically large and powerful animals are bad characters in some books. Based on the findings obtained, it is thought that children may exhibit negative attitudes and behaviors especially against animals that have bad character traits. For this reason, it is recommended that children should pay attention to the content of the books and families in the books and animals in which the animals are used as characters.
\end{abstract}

Keywords: Children's books, animal, early childhood, environmental education, content analysis

\section{EXTENDED ABSTRACT}

\section{Introduction}

Books in early childhood are one of the most important tools of the educational process. The children's books directly and indirectly convey a large number of information through the plot and their heroes. Books are used in all disciplines of education. In this respect, environmental education is an area that frequently uses books. Although the number of environmental-themed books increases day by day, there are a number of books whose aim is not direct environmental education. Because these books address children, they use human or animal characters.

Animal characters in the book are presented to the reader in a generalized way. In the meantime, they are influenced by the thought systems of the period and the cultures in which they were written. This effect also affects the characteristics of animal characters. Good and bad characteristics of culture are reflected in these animals. Especially at a young age, these characteristics in the characters of the

\footnotetext{
${ }^{1}$ Kastamonu Üniversitesi, arife.pkrr.789@gmail.com, ORCID: 0000-0002-7691-2688

${ }^{2}$ Doç. Dr.,Kastamonu Üniversitesi, Eğitim Fakültesi, beratahi@gmail.com, ORCID: 0000-0002-8744-7213
} 
book can affect children deeply. A good or bad feature in any animal character may cause the child to develop negative feelings and thoughts about the animal.

In terms of environmental education, this situation can enable the child to develop a negative thought against the animal. This may cause the child to develop prejudice against the animal without understanding the ecological niche. This kind of thoughts at a young age can be seen as a negative attitude towards the environment and animals in the future. For this reason, it is important to know which animals are found in the books, how these animals are transferred to the child and the character of the animal is due to the physical and aesthetic characteristics of the animal. Although there are numerous studies analyzing anaphylax in terms of environment, the number of studies involving animal analyzes is very limited. For all these reasons, this study determines to the following questions.

- What are the animals involved in children's books and how are their roles distributed?

- How are the animal characters in children's books reflected through messages?

\section{Method}

The research is designed according to qualitative research paradigms and structured according to content analysis which is one of the qualitative research techniques. Content analysis used in the social sciences and frequently used in qualitative research is a systematic, repeatable technique in which some words of a text are summarized with smaller content categories based on certain rules. The fundamental process in content analysis is to bring together similar data in the context of specific concepts and themes and to interpret them in a way that the reader can understand.

The study group was composed of 51 books of two different publishing houses. The reason for these two different publishing houses is the working group; the fact that publishing houses are accessible everywhere and a significant portion of their corpuscles are divided into animal character books. Firstly 60 books were identified. However, the presentation of the animal characters of nine books did not overlap with the purpose of the study and they were not included in the study group due to their way of functioning. In the research, content analysis was used from the qualitative data analysis methods for in-depth analysis of the characters within the text. Before the content analysis, the books were read by the researchers and those who were suitable for the study group were selected. These researchers then re-read the books for the content analysis process. After reading, each book was subjected to a separate review. At the same time, the codes were introduced simultaneously. First of all, the animals in the books are determined and the characters of the animals are categorized as good and old bad. In this way, as to how the animals were projected, data were obtained to determine which animal has a character. While doing this, it was examined how animals are emphasized aesthetically or physically. In the scope of the research, aesthetic animal characteristics are formed by variables such as sound, image structure, animal being beautiful or ugly in the book. In the next stage, the sentences that reflect the character characteristics of these animals are placed in the relevant codes. When the researchers could not reach a consensus among themselves, their opinions were requested from a third expert and the final decision was made in line with the opinion. In order to determine the compatibility between the codes and themes produced by the expert and the codes and themes of the researchers, the Kappa Compliance Index was calculated and the index was determined to be .86. According to Peat (2001, p. 228), Kappa value above .8 indicates that very good fit is achieved.

\section{Result and Discussion}

In the study group, 41 different species of animals were characterized. In the books, the most common animals are birds $(\mathrm{n}=12)$, ants $(\mathrm{n}=12)$ and bear $(\mathrm{n}=11)$ animals; sheep, bee, camel, donkey, squirrel, whale, chameleon etc. animals of different classes and species have been characterized only once. However, a total of 41 animals are presented as having good character. Among the most (good ay1 characters among them are bird $(\mathrm{n}=12)$, ant $(\mathrm{n}=6)$, rabbit and bear $(\mathrm{n}=8)$. In addition, 10 different animals were reflected as "bad Buna characters. These are bear $(n=3)$, wolf $(n=3)$, tiger $(n=2)$, fox $(\mathrm{n}=3)$, rhino $(\mathrm{n}=1)$ and so on. Here, the bear is an animal that is often reflected in both bir good yansit and "bad" characters. Apart from this, almost all of the animals with bad characters are composed of animals in the class of predators. In animals characterized as tedir good dikkat, creatures such as birds, ants and rabbits attract attention. According to this, it was concluded that the predators in children's 
books are generally reflected as bad, while the animals that come face to face in everyday life and who are close to human in terms of physical, aesthetic and life are reflected.

Among the animals in the books, the most dominant characteristics are cunning, being strong and intelligence. A significant proportion of animals are reflected in the focus of their forces. Ir The bear got angry at the duck and sent it to the other side of the glacier and the lion saying no, he got angry and threw him into the air aya. Again, very often emphasized cunning animals such as foxes, wolves and frogs come to the fore. Especially the fox as if I ask who is the most cunning of all animals, I hear you shout (Meraklı Karınca Cimcim' in Serüvenleri, YKY).

Animals with good characters are generally well-hearted, intelligent and hard-working. Animals with this character structure are generally presented as leading characters who sacrifice to save other animals from problems in the plot, or to save their entire habitat from danger. When the messages are examined, there are many sentences with emphasis on this. Apart from predators, in terms of physical characteristics, large animals are also given features that can be called bad. The most common feature of these animals is that they are frustrated or use force. When the mouse encounters a bear in his book 'Fare in the Book eyen, eyen the bear grabbed the mouse by the tail, raised him upwards, and looked upside down and dropped onto the ice eyen.

\section{GİRIŞ}

Günümüzde okul öncesi dönemde çocukların gelişiminin desteklenmesinde ve eğitiminde resimli kitapların önemi gittikçe artmaktadır. Modern anlamda çocukluğun keşfi, Avrupa ve Amerika' da sanayi devrimi dönemine kadar uzanır. Buna rağmen çocuk edebiyatının eğitim ve öğretimde kullanılmasının önemi görece çok daha yenidir gibi düşünülse de, bunun temelleri çok uzun zaman öncesinde atılmıştır. Özellikle filantropi felsefesinin eğitimde kendine yer edinmesiyle kitaplar, erken çocukluk eğitiminde kullanılmaya başlanmıştır. Filantropizm' in öncülerinden Basedow (1724-1790) ve Salzmann (1744-1811) kurdukları okullarda kitapları önemli bir ders aracı olarak görmüş ve çocukları hayata hazırlama ve tanıtmada önemli unsurlar olduklarını savunmuşlardır (Bekir, 1930). Kitapların eğitim için kullanılmasının tarihi çok eskilere dayansa da, son zamanlarda önemi daha da anlaşılan çocuk kitaplarının basım ve yayımındaki profesyonel anlayış ise görece daha yenidir. Uğurlu (2013) bu yeni anlayışta çocuğa verilen bilginin sıkıcı ve tek düze olmasındansa; sanatsal niteliği ön planda olan metin ve resmin, baskı, kâğıt ve kapak tasarımının kaliteli olarak sunulmasıyla eğitimde bu tekdüzeliğin giderilebileceğini belirtmektedir.

Kitaplar çocukların yaşamlarının daha ilk yılında hayatlarına girerler. Çocuk kitaplarındaki resimler ve metinler çocukların duygu ve düşünce dünyasını harekete geçirir. Bununla birlikte bir iletişim aracı olarak çocuğun dil gelişimi, alıcı ve ifade edici dil becerilerini destekleyici rol oynar (Güleç ve Gönen, 1997; Şahin, 2014). Kitaplar bu iletişimi görselleri veya metinlerin içerisinde yer alan fikirlerle sunarlar. Roxburg, Zolotow, L'Engle ve Kruse (1982) bir çocuk kitabının "iyi”" olabilmesi için çocuğun duygu ve düşünce dünyasını harekete geçirmesi gerektiğini belirtirler. Horsman (2014) günümüz çocuk kitaplarının içerisinde yer alan karakterlerin temelde kapitalist ve modernist bir anlayışla kaleme alınmış, pragmatik bakış açılarına sahip olduğunu ve verdikleri mesajlarında doğal olarak bu bakış açısını içerdiğini savunur. Genel olarak erken çocukluk dönemine yönelik kitap karakterleri hayvan veya insan olur. Bu iki türün etkileşimi genel olarak kitapların olay örgüsünü oluşturur (Horsman, 2014; McCrindle \& Odendaal, 1994). Erken çocukluk dönemi çocuğunun gelişim ve eğitim sürecinin sağlıklı olması için, kişileştirilmiş değişik hayvan, bitki ve diğer doğa öğeleriyle bezeli resimler, çocuk kitapları aracılığı ile çocuk okurun karşısına çıkmaktadır. Bu yüzden çocuk kitaplarında yer alan karakterler, çocuk okurun sosyalleşme sürecinde etkili olduğu kadar, çocuk okura birtakım iletileri vermek ve onun karakterini geliştirmek açısından da önemlidir (Yılmaz, 2016). Yazıcı Okuyan ve Gedikoğlu (2012) de erken çocukluk dönemi çocuğuna bilinç ve duyarlılık kazandırmada çocuk kitaplarının önemli bir yer tuttuğunu belirtmektedirler.

Çocuklar için eğitimsel ve gelişimsel pek çok önemli kazanımı içinde barındıran kitaplar onların ilgilerini çekecek karakter ve olay örgüsü içermektedir. Özellikle erken çocukluk dönemi çağ içerisindeki bir çocuğun animistik ve artifikalistik düşünce sistemine sahip olmaları (Piaget, 1947) 
hayvan karakterlerin insan gibi karakterize edildiği kitapları çok daha dikkat çekici kılmaktadır. Çünkü çocukların canlandırma ve yapaylaştırma ile nöro-bilişsel düzeydeki şemayı (bilgi) oluşturma becerisi oldukça güçlüdür (Piaget, 1947). Bu da çocukların, içerisinde hayvanların konuştuğu, insan gibi davrandığı ve olay örgüsü içerisinde önemli yer tuttuğu kitaplara olan ilgilerini arttırmaktadır (Uğurlu, 2013). Bu karakterler aracılığıyla; çocukta hayvan ve doğa sevgisinin yerleşmesi, hayvanlara yönelik yaşıyla orantılı çabalar içine girmesi ve sonucunda bulunduğu kültüre ait değerleri edinmesi hedeflenir, çünkü her kitap karakteri bulunduğu zamanın ruhunu (zeitgeist) ve kültürel kimliğini taşır (Williams, 2014). Kitap karakterinin taşıdığı tüm bu altyapı ve Horsman (2014)' in belirttiği çağın temel düşünce akımlarından etkilenmesi hadisesi, kitapları çağın gerektirdiği bazı özellikleri barındırmalarına neden olmaktadır. Bedford (2012) hayvan karakterlerin başrolde olduğu kitapların en temel özelliğinin problem çözme becerisi olduğunu vurgulamaktadır. Yazara göre bu problemler bazen bir insanın toplum içerisinde karşılaştığ 1 türden olurken, bazen de tamamen hayvanların kendi habitatlarından kaynaklı olmaktadır. Sonuçta hayvan karakterler çocuk kitaplarının önemli bir bölümünde yer alır ve çocuklar arasında bu tarz kitaplar oldukça popülerdir (Bedford, 2012; McCrindle ve Odendaal, 1992).

Hayvan karakterlere sahip kitapları okuyan çocuklar hayvanlarla duygudaşlık içine girerler (Trupe, 2006; Uğurlu,2013). Asıl amaç genellikle çocukların özverili, yardımsever, saygılı, sadık, vb. istendik davranışlara sahip bir birey olmalarına yardımcı olmaktır (Oğuzkan, 2010; Demirel, Çeçen, Seven, Tozlu ve Uludağ, 2011; Yıldırım, 2012; Yılmaz, 2016). Ancak bunun gerçekleşebilmesi için de kitaplardaki bazı karakterler "iyi" olurken, bazılarının ise "kötü" olması gerekir. McCrindle ve Odendaal (1992) kitaplarda yer alan hayvanların çok büyük bir bölümünün (\%43.2) gerçekçi olarak yansıtıldığ1, yine önemli bir bölümünün de (\%30.1) insanlaştırarak hayvanı yansıttığını tespit etmişlerdir. Kurgusal olarak bunun en önemli nedeni insanın hatalı ve kusurlu yanlarını örtük bir şekilde yansıtmak istemesidir (Sınar, 2007; Yılmaz, 2016). Çünkü bir olay örgüsünün hayvan karakterler üzerinden anlatılması, yapılan eleştirinin örtük bir şekilde ilgili kişiye veya yere ulaşmasını sağlar (Yalçın ve Aytaş, 2008; Yılmaz, 2016). Tüm bunlar hayvan karakterini de "iyi” veya "kötü" olarak ayırma zorunluluğunu getirmektedir.

Bu durum genel olarak hayatın olağan akışı içerisinde normal karşılanmaktadır. Ancak özellikle hayvan karakterler iyi veya kötü rollerle yansıtıldığında çevre eğitimi noktasında önemli sorunlar ortaya çıkabilmektedir. Çevre eğitimi yapısı gereği çoklu-disipline sahip bir alandır. Edebiyat, çevre eğitiminin önemli paydaşlarındandır (Yazıcı Okuyan ve Gedikoğlu, 2012). Özellikle kitaplar erken çocukluk döneminde çocuğa bilinç ve duyarlılık kazandırmada önemli bir yer tutar (Derman ve Aslan, 2016). Çevre eğitimi açısından bakıldığında insan ve doğa arasındaki ilişkinin istenilen boyutlara gelebilmesi için hayvanlar hakkında geliştirilen tutumun, değerin ve bilginin önemi çok fazladır. Ancak çocuk kitapları hayvanları iyi ve kötü hayvanlar olarak ikiye ayırır. Zararlı ve işe yaramaz olarak nitelendirilen hayvanlar kötü olarak kabul edilirken, evcil hayvanlar iyi olarak kabul edilir. İyi hayvanlar köpek, kedi, balık vb. evcil hayvanlar; kötü hayvanlar ise örümcek, yarasa, yılan vb. gibi yırtıcı ve sürüngenlerden seçilmektedir (Kubiatko, 2012; Ahi, 2016). Bu durumda genel yargılar hayvanların görünüşlerine, evde beslenip beslenemeyeceğine göre şekillenmektedir. Ancak sonuçta her hayvanın doğada bir ekolojik nişi vardır. Bu nedenle her canlı kendi habitatı hatta biyosfer için eşsiz ve önemlidir. Çocuk kitaplarında yer alan hayvan karakterler de tıpkı insan karakterler gibi onların duygu ve düşünce dünyalarında kalıcı izler bırakabilir (Bedford, 2012). Bu nedenle hayvana ait yerleştirilen bazı özellikler (iyi veya kötü) çocukların düşünce dünyalarında yer edinir. Çocuk ve hayvan arasındaki ilişki, çocuğun sosyalduygusal gelişiminin yanı sıra, hayvana ait biyolojik ve ekolojik bilgi de içerdiğinden akademik yönlere de sahip olabilir (Tipper, 2011). Bjerke, Kaltenborn ve Ødegårdstuen, (2001) vahşi yaşam olarak adlandırılan habitata ait hayvanları tanımanın ve buradaki yaşamı anlamanın çocuğa çok daha yoğun biyolojik ve ekolojik bilgi sunarak hayatı anlamlandırmayı kolaylaştırdığını savunmaktadır. Bununla birlikte çocuğun gündelik yaşamında hayvanlara yönelik ne kadar çok deneyim elde ederse onu tanıma ve olumlu tutum geliştirme konusunda da o derece başarılı olabilmektedir (Borgi ve Cirulli, 2015). Aksi durumda ise çocuk hayvanın biyosferdeki öneminden bağımsız olarak kitapta yansıtılan olumsuz özellikler aracılığıyla, söz konusu hayvana karşı olumsuz tutum sergileyebilmektedir (Hawkins ve Williams, 2016).

Tüm bunlardan hareketle çocuk kitaplarında yer alan hayvanların sahip oldukları karakteristik özellikleri çocuğun ona olan bakış açısını etkilediğinden çevre eğitimi açısından da kitaplara ve yazarlara ek sorumluluklar yüklemektedir. Bu nedenle de kitapları yer alan hayvan karakterlerinin alışılagelmiş kalıplarından çıkartılarak, iletiler aracığı ile özgün bir şekilde, nasıl yansıtıldığının 
saptanması hem çevre eğitimi hem de çocuk edebiyatı için önemlidir. Ayrıca yapılan pek çok araştırma (Ahi, 2016; Bjerke, Kaltenborn \& Ødegårdstuen, 2001; Borgi \& Cirulli, 2015; Hawkins \& Williams, 2016, Prokop, Prokop, Tunnicliffe \& Diron, 2007) çocukların hayvanlara yönelik tutumuna odaklanmışken, çocukların hayvanlara yönelik tutumunda çocuk kitaplarının önemi noktasında çok sınırlı araştırma (Örn. McCrindle ve Odendaal, 1992) yapılmış̧ır. Tüm bunlara ek olarak erken yaşlarda çocukların hayvanları anlamlandırma ve tanıması açısından öncü kaynaklardan olan kitapların hangi hayvanı nasıl yansıttığının anlaşılması çocukların hayvanlara yönelik tutumlarının da anlaşılmasını kolaylaştırabileceğinden yapılan bu araştırma araştırmacılar tarafından önemli görülmektedir. Söz konusu araştırmanın amacı çocuk hikâye kitaplarında yer alan hayvanların karakteristik özellikleri açısından nasıl yansıtıldıklarını anlamak ve bu hayvan karakterleri üzerinde verilen iletileri belirlemektir. Bu amaç doğrultusunda aşağıdaki sorulara cevap aranmaktadır:

- Çocuk kitaplarında yer alan hayvanlar nelerdir ve karakterlerinin rol dağılımları nasıl kurgulanmıştır?

- Çocuk kitaplarında yer alan hayvan karakterleri iletiler aracılığıyla nasıl yansıtılmıştır?

\section{YÖNTEM}

Araştırma nitel araştırma paradigmalarına göre tasarlanmış olup, nitel araştırma tekniklerinden biri olan içerik analizine uygun olarak yapılandırılmıştır. Sosyal bilimler alanında yapılan farklı disiplinlerdeki pek çok araştırmada kullanılan içerik analizi, bulgulara yönelik kurallara dayanan kodlamalarla, bir içeriğin daha küçük içerik kategorileri ile özetlendiği sistematik ve tekrarlanabilir bir tekniktir (Büyüköztürk, 2013; Çeçen ve Akaydın, 2015). İçerik analizinde amaç, birbirine benzeyen verileri bir araya getirerek, okuyucunun anlayabileceği şekilde bulguları vurgulamaktır (Yıldırım ve Şimşek, s. 227; Çeçen ve Akaydın, 2015). Aynı zamanda bu analiz yöntemi bir alanda var olan alanyazını değerlendirmeye yardımcı olan bir yöntemdir (Falkingham ve Reeves, 1998). İçerik analizi, çeşitli materyallerin sistemli bir şekilde incelenerek oluşan kategoriler açısından tematik olarak analiz edilmesini kapsayan (Hazır-Bıkmaz, Aksoy, Tatar ve Atak Altınyüzük, 2013; Saban, 2009) bir yöntem olduğu için çalışmanın genel amacının da resimli öykü kitaplarındaki hayvanların yansıtılma biçimlerini anlamak olduğundan araştırma modelinin araştırma problemini desteklediği düşünülmektedir.

\section{1. Çalışma Grubu}

Araştırmanın çalışma grubu, iki farklı yayınevinin 51 kitabı ele alınarak oluşturulmuştur. Bu iki farklı yayınevinin çalışma grubunu oluşturmasının nedeni; yayınevlerinin her yerde ulaşılabilir olması ve külliyatlarının önemli bir bölümünü hayvan karakterli kitaplara ayırmış olmalarıdır. İlk olarak 60 kitap tespit edilmiştir. Ancak dokuz kitabın hayvan karakterleri sunuş şekilleri araştırmanın amacıyla örtüşmediğinden ve konularını işleyiş tarzlarından dolayı çalışma grubuna alınmamışlardır.

Araştırmada kullanılan kitap serisi kriter örnekleme yöntemiyle belirlenmiştir. Kriter örnekleme yöntemi nitel araştırmalarda sıklıkla kullanılan ve belirlenen ölçütler sayesinde araştırma amacına hizmet eden tüm verileri yakalamayı hedeflemektedir (Patton, 2014). Buna göre ilk ve en önemli kriter çocuk hikâye kitaplarında olayların 'hayvan karakterleri' çerçevesinde kurgulanmasıdır. İkinci kriter ise kitaplarda bir olay örgüsünün olmasıdır. Üçüncü ve son kriter ise hayvanların belirli rollere dayalı olarak karakterize edilmelerdir. Söz konusu yayınevlerinin kriterleri sağlayan kitapları Tablo 1'de gösterilmiştir 
Tablo 1. Çalışma Grubunu Oluşturan Kitapların Künyelerine İlişkin Bilgiler

\begin{tabular}{|c|c|c|c|}
\hline Kitabın Adı & Yazarın Adı & Yayınevi & Yilı \\
\hline Pembe Karga & Helga Bansch & YKY & 2013 \\
\hline Sanatçı Olmak İsteyen Kurt & Orianne Lallemand & YKY & 2013 \\
\hline Uğurböceği Sevecen İle Salyangoz T. & Erika Bartos & YKY & 2014 \\
\hline Mesajın Var Kırlangıç & Julia Donaldson & 1001 Çiçek & 2015 \\
\hline Denizi Görmek İsteyen Meraklı Tavuk & Christian Jolibois & 1001 Çiçek & 2016 \\
\hline Sevgili Babacığım & Daniel Howerth & 1001 Çiçek & 2017 \\
\hline Karınca İle Ağustos Böceği & Lesley Sims & 1001 Çiçek & 2017 \\
\hline Okula Gitmek İstemeyen Zebra & Chiristine Beigel & 1001 Çiçek & 2017 \\
\hline Uykuya Dalamayan Koyun & Chiristine Beigel & 1001 Çiçek & 2017 \\
\hline Yatağını Islatan Kanarya & Chiristine Beigel & 1001 Çiçek & 2017 \\
\hline Valentine İle Koca Ayı Aynı Okulda & Orianne Lallemand & 1001 Çiçek & 2017 \\
\hline Kaplanı Kandırmak & Julia Donaldson & 1001 Çiçek & 2017 \\
\hline İyi Geceler Farecikler & Frances Watts & 1001 Çiçek & 2017 \\
\hline Prensesin Köpeği & Aleix Cabrera & 1001 Çiçek & 2017 \\
\hline Ayılar Kitap Okumaz & Emma C.Clark & 1001 Çiçek & 2017 \\
\hline Haylaz Timsah Dişlerini Nasıl Fırçalar? & Jane Clarke & 1001 Çiçek & 2017 \\
\hline Uykucu Aslan Nasil Uyur? & Jane Clarke & 1001 Çiçek & 2017 \\
\hline Minik Dinozor Nasıl Banyo Yapar? & Jane Clarke & 1001 Çiçek & 2017 \\
\hline Gergedanın Derisi Neden Buruş Buruș? & Rudyard Kipling & 1001 Çiçek & 2017 \\
\hline Prensesin Kedisi & Aleix Cabrera & 1001 Çiçek & 2017 \\
\hline Cesur & Colin Thompson & 1001 Çiçek & 2017 \\
\hline Gece Maymunu-Gündüz Maymunu & Julia Donaldson & 1001 Çiçek & 2017 \\
\hline Kahraman Olmak İsteyen Tavşan & Alexandre Chardin & 1001 Çiçek & 2017 \\
\hline Zuzu İle Uykucu Baykuş & Görkem K. Arsoy & YKY & 2017 \\
\hline Meraklı Karınca Cimcim'in Serüvenleri & Bilgin Adalı & YKY & 2017 \\
\hline Yeni Komşumuz Komo & Yasemin Özer & YKY & 2017 \\
\hline Bir Gün Tavşan Kralken & Yasemin Özer & YKY & 2017 \\
\hline Neşeli Ormanın Bateristleri & Berat Alanyalı & YKY & 2018 \\
\hline Kayıp Çocuklar Bahçesi & Doğan Gündüz & YKY & 2018 \\
\hline Toko & Naz Elkorek & YKY & 2018 \\
\hline Bal Avcısı Küçük Piti & Yalvaç Ural & YKY & 2018 \\
\hline Zuzu İle Kaplan Yongi & Görkem K. Arsoy & YKY & 2018 \\
\hline Hediyesin İsteyen Fare & Chiristine Beigel & 1001 Çiçek & 2018 \\
\hline Erken Kalkmayı Sevmeyen Kurbağa & Chiristine Beigel & 1001 Çiçek & 2018 \\
\hline Annesini Arayan Bukalemun & Chiristine Beigel & 1001 Çiçek & 2018 \\
\hline Ünlü Olmak İsteyen Tembel Hayvan & Chiristine Beigel & 1001 Çiçek & 2018 \\
\hline Ayı Söndürmek İsteyen İnek & Chiristine Beigel & 1001 Çiçek & 2018 \\
\hline Kötü Sözler Söyleyen Koala & Chiristine Beigel & 1001 Çiçek & 2018 \\
\hline Sudan Korkan Timsah & Chiristine Beigel & 1001 Çiçek & 2018 \\
\hline Uyku Arkadaşını Arayan Ayı & Chiristine Beigel & 1001 Çiçek & 2018 \\
\hline Hiçkırık Tutan Su Aygırı & Chiristine Beigel & 1001 Çiçek & 2018 \\
\hline Her Şeye Hayır Diyen Aslan & Chiristine Beigel & 1001 Çiçek & 2018 \\
\hline Şekeri Çok Seven Kurt & Chiristine Beigel & 1001 Çiçek & 2018 \\
\hline Ayakları Üşüyen Penguen & Chiristine Beigel & 1001 Çiçek & 2018 \\
\hline Banyo Yapmak İstemeyen Zürafa & Chiristine Beigel & 1001 Çiçek & 2018 \\
\hline Bitlenen Panda & Chiristine Beigel & 1001 Çiçek & 2018 \\
\hline Karnı Aç Boa Yılanı & Chiristine Beigel & 1001 Çiçek & 2018 \\
\hline Fificik & Chiristine Beigel & 1001 Çiçek & 2018 \\
\hline Afacan Maymun Nasıl Yemek Yer? & Jane Clarke & 1001 Çiçek & 2018 \\
\hline Obur Balina & Rudyerd Kipling & 1001 Çiçek & 2018 \\
\hline Tilki ve Sincap'ın Yeni Arkadaşı & Ruth Oni & 1001 Çiçek & 2018 \\
\hline
\end{tabular}




\subsection{Veri Analizi}

Araştırmada metin içinde yer alan karakterlerin derinlemesine çözümlemesi için nitel veri analizi yöntemlerinden içerik analizi kullanılmıştır. İçerik analizine başlamadan önce kitaplar araştırmacılar tarafından okunmuş ve çalışma grubuna uygun olanlar seçilmiştir. Sonrasında bu araştırmacılar kitapları içerik analizi süreci için yeniden okumuşlardır. Okuma işleminden sonra her kitap ayrı ayrı incelemeye tabi tutulmuştur. İnceleme süreciyle eş zamanlı olarak kodlar ortaya çıkarılmaya başlanmıștır. Öncelikli olarak kitaplarda yer alan hayvanların neler oldukları belirlenmiş ve hayvanların karakterleri "iyi" ve "kötü” olarak kategorilere ayrılmıştır. Bu sayede hayvanların nasıl yansıtıldığ 1 ortaya çıkarıldığı gibi hangi hayvanın nasıl bir karaktere sahip olduğu sonucuna yönelik veriler de elde edilmiştir. Bu işlem yapılırken beraberinde hayvanların estetik olarak veya fiziksel olarak nasıl vurgulandığına da bakılmıştır. Araştırma kapsamında estetik hayvan özellikleri ses, görüntü yapısı, kitap içerisinde hayvanın güzel veya çirkin olarak lanse edilmesi gibi değişkenlerle oluşturulurken, fiziksel özellikler genel olarak vücut yapısı ve güç üzerinden yorumlanmıştır. Sonraki aşamada ise bu hayvanların metin içerisindeki karakter özelliklerini yansıtan cümleler ilgili kodların içerisine yerleştirilmiştir. Araştırmacıların kendi aralarında fikir birliğine varamadığı durumda üçüncü bir uzmandan görüşleri istenmiş ve görüş doğrultusunda son karara varılmıştır.

Araştırmacıların içerik analizi süreci üç aşamadan oluşsa da benzer bir süreç bir çocuk edebiyatı uzmanı tarafından da yürütülmüş ve kod ve temaları çıkarması istenmiştir. Uzmanın ürettiği kod ve temalar ile araştırmacıların kod ve temaları arasındaki uyumu tespit edebilmek amacıyla Kappa Uyum İndeksi hesaplanmış ve indeks .86 olarak tespit edilmiştir. Peat (2001, s. 228)' e göre .8 üstü Kappa değeri çok iyi uyumun yakalandığının göstergesidir. Araştırmacı ve uzmanın görüşleri sonrasında uyumsuz bulunan kod ve temalar yeniden gözden geçirilmiş ve hep birlikte nihai karara varılmıştır. Ortak karar verilmeyen veriler aşırı uç (outliers) olarak değerlendirilip kapsam dışı bırakılmıştır. Böyle iki adet kod vardır. Alanyazında aşırı uç ayıklama işlemi sadece nicel araştırma odaklı yapılsa da (Pallant, 2011), nitel araştırmalarda da benzer ayıklama işlemleri yapılabilmektedir (Peat, 2001).

Ayıklama işlemi sonrasında verilerin son hali nitel araştırma uzmanına gösterilmiş, süreçten bahsedilmiş ve yapılan işlem basamakları tek tek açıklanmıştır. Uzmanın da onayı sonrasında elde edilen verilerin bulguya dönüştürülmesi için gerekli işlemler başlamış ve bulguların raporlanması sürecine geçilmiştir. Bu sayede araştırmacılar Kappa Uyum İndeks ile güvenirliği uzmanlarla süreci yeniden yapılandırarak geçerliği kontrol altına almayı amaçlamışlardır.

\section{BULGULAR}

İçerik analizi sonucunda ilk olarak incelenen kitaplarda hangi hayvanların yer aldığı, söz konusu hayvanların metin içindeki karakterlerinin özelliğine ait dağılımlar Tablo 2' de gösterilmiştir 
Tablo 2. Çocuk Hikaye Kitaplarında Yer Alan Hayvanların Rol Dağıllımı

\begin{tabular}{|c|c|c|c|}
\hline Hayvanlar & $\dot{\text { Iyi Karakter }}$ & Kötü Karakter & $\bar{F}$ \\
\hline Karınca & 12 & - & 12 \\
\hline Kuş & 12 & - & 12 \\
\hline Ay1 & 8 & 3 & 11 \\
\hline Tilki & 5 & 3 & 8 \\
\hline Köpek & 3 & 4 & 7 \\
\hline Maymun & 5 & 2 & 7 \\
\hline Kurt & 3 & 3 & 6 \\
\hline Aslan & 4 & 2 & 6 \\
\hline Tavşan & 6 & - & 5 \\
\hline Karga & 3 & 1 & 4 \\
\hline Köpek & 4 & - & 4 \\
\hline Yilan & 3 & 1 & 4 \\
\hline Kurbağa & 2 & 1 & 3 \\
\hline Fare & 3 & - & 3 \\
\hline Kaplan & 1 & 2 & 3 \\
\hline Uğur Böceği & 3 & - & 3 \\
\hline Koyun & 1 & - & 1 \\
\hline Ar1 & 1 & - & 1 \\
\hline Eşek & 1 & - & 1 \\
\hline Sincap & 1 & - & 1 \\
\hline Balina & 1 & - & 1 \\
\hline Bukelamun & 1 & - & 1 \\
\hline Su Aygirı & 1 & - & 1 \\
\hline Fil & 1 & - & 1 \\
\hline Kedi & 1 & - & 1 \\
\hline Zebra & 1 & - & 1 \\
\hline Koala & 1 & - & 1 \\
\hline Tavuk & 1 & - & 1 \\
\hline Timsah & 1 & - & 1 \\
\hline Sincap & 1 & - & 1 \\
\hline Panda & 1 & - & 1 \\
\hline Dinozor & 1 & - & 1 \\
\hline Penguen & 1 & - & 1 \\
\hline Ahtapot & 1 & - & 1 \\
\hline A ğustos Böceği & - & 1 & 1 \\
\hline Domuz & 1 & - & 1 \\
\hline Kaplumbağa & 1 & - & 1 \\
\hline İnek & 1 & - & 1 \\
\hline Gergedan & - & 1 & 1 \\
\hline Deve & - & 1 & 1 \\
\hline Solucan & 1 & - & 1 \\
\hline
\end{tabular}

Tablo 2 incelendiğinde çalışma grubunda yer alan kitaplarda 41 farklı türde hayvan karakterize edilmiştir. Kitaplarda en çok sırasıyla: kuş $(n=12)$, karınca $(n=12)$ ve ayı $(n=11)$ hayvanlarına yer verilirken; koyun, arı, deve, eşek, sincap, balina, bukalemun vb. farklı sınıf ve türden hayvanlara sadece bir kez karakterize edilmişlerdir. Bununla beraber toplam 41 hayvanın tamamı iyi karaktere sahip olarak sunulmuştur. Aralarında en çok "iyi” karaktere sahip olarak sunulanlar ise, kuş $(n=12)$, karınca $(n=6)$, tavşan ve ayıdır $(n=8)$. Buna ek olarak 10 farklı hayvan ise "kötü" karaktere sahip olarak yansıtılmıştır. Bunlar da, ayı $(n=3)$, kurt $(n=3)$, kaplan $(n=2)$, tilki $(n=3)$, gergedan $(n=1)$ vb. Burada ayı hem "iyi" hem de "kötü" karakterde sıklıkla 
yansıtılan bir hayvandır. Bunun dışında kötü” karaktere sahip hayvanların neredeyse tamamı yırtıc1 (apex predator) sinıfinda yer alan hayvanlardan oluşmuştur. “'̇yi” olarak karakterize edilen hayvanlarda ise kuş, karınca, tavşan gibi canlılar dikkat çekmektedir. Buna göre çocuk kitaplarında genellikle yırtıcılar kötü olarak yansıtılırken, gündelik yaşamda karşımıza çıkan ve fiziksel, estetik ve cana yakınlık anlamında insana yakın olan hayvanların "iyi” olarak yansıtıldığ 1 sonucuna ulaşılmıştır.

Tablo 3. Hayvanların Kitaplarda Kurgulanış Biçimleri

\begin{tabular}{|c|c|c|c|}
\hline Hayvanlar & Baskın Özellik & Vurgulanma Şekli & Ekolojik Niş Vurgusu \\
\hline Ağustos Böceği & Tembel & Fiziksel & Yok \\
\hline Ahtapot & Yardımsever & Fiziksel & Yok \\
\hline Ar1 & Çalışkan & Fiziksel & Yok \\
\hline Aslan & Güçlü, adil, lider & Fiziksel v Estetik & Yok \\
\hline Ay1 & Güçlü, kurnaz, yardımsever & Fiziksel & Yok \\
\hline Balina & Güçlü & Fiziksel & Yok \\
\hline Bukalemun & Saf & Fiziksel & Yok \\
\hline Deve & Güçlü & Estetik & Yok \\
\hline Dinozor & Güçlü & Fiziksel v Estetik & Yok \\
\hline Domuz & Sicakkanlı & Estetik & Yok \\
\hline Eşek & İnatçı & Fiziksel & Yok \\
\hline Fare & Uyanık & Fiziksel & Yok \\
\hline Fil & Güçlü & Fiziksel & Yok \\
\hline Gergedan & Güçlü & Fiziksel ve Estetik & Yok \\
\hline İnek & Saf & Fiziksel & Yok \\
\hline Kaplan & Güçlü ve hızlı & Fiziksel & Yok \\
\hline Kaplumbağa & Sakin & Fiziksel & Yok \\
\hline Karga & Geveze, zeki & Estetik & Yok \\
\hline Karınca & Çalışkan & Fiziksel ve Estetik & Yok \\
\hline Kedi & Bencil, sevimli & Estetik & Yok \\
\hline Koala & Tembel & Estetik & Yok \\
\hline Koyun & Dost canlis1 & Fiziksel & Yok \\
\hline Köpek & Sicakkanlı, sadık & Fiziksel & Yok \\
\hline Kurbağa & Kurnaz & Estetik & Yok \\
\hline Kurt & Kurnaz & Fiziksel & Yok \\
\hline Kuş & Sicakkanlı & Estetik & Yok \\
\hline Maymun & Hizlı ve hareketli & Fiziksel & Yok \\
\hline Panda & Tembel ve sevimli & Estetik & Yok \\
\hline Penguen & Oyuncu & Fiziksel & Yok \\
\hline Salyangoz & Yavaş & Estetik & Yok \\
\hline Sincap & Uyanık ve hızlı & Estetik & Yok \\
\hline Solucan & Yardımsever & Estetik & Yok \\
\hline Su Aygırı & İnatçı & Fiziksel & Yok \\
\hline Tavşan & Fedakâr, cesur & Fiziksel & Yok \\
\hline Tavuk & Ak1ll1, yardımsever & Estetik & Yok \\
\hline Tilki & Kurnaz, üçkağıtçı & Fiziksel & Yok \\
\hline Timsah & Güçlü & Fiziksel & Yok \\
\hline Uğur Böceği & Sevimli & Estetik & Yok \\
\hline Yilan & Yardımsever & Fiziksel v Estetik & Yok \\
\hline Zebra & Paylaşımcı & Estetik & Yok \\
\hline Zürafa & Sakin & Fiziksel & Yok \\
\hline
\end{tabular}

Tablo 3' te kitaplarda yer alan hayvanların genel olarak nasıl kurgulandıkları gösterilmiştir. Tablo 3 incelendiğinde kitaplarda yer alan hayvanların arasında en baskın özelliklerin kurnazlık, güçlü olma ve zeka olduğu görülmektedir. Hayvanların önemli bir bölümü güçleri odağında yansıtılmıştır. 'Ayl 
ördeğe sinirlendi ve onu buzulun öbür tarafina gönderdi, hayır diyen aslana da sinirlenerek havaya firlattı' iletisinden de anlaşılacağı gibi ayı, kaplan, aslan ve gergedan da güç daha çok doğadaki diğer canlılar üzerinden anlatılmaktadır. Yine çok sık vurgulanan kurnazlıkta tilki, kurt, kurbağa gibi hayvanlar ön plana çıkmaktadır. Özellikle tilki 'Bütün hayvanların içinde en kurnazı kim diye sorsam tilki diye bağırdığınızı duyar gibiyim' (Meraklı Karınca Cimcim' in Serüvenleri, YKY) gibi iletiyle daha baştan okuyucunun hayvanın karakterine yönelik tanıtıcı vurguyla yansıtılmaktadır.

Bununla birlikte kitaplarda yer alan hayvanların çok büyük bir bölümü fiziksel özellikleri üzerinden karakterize edilmiştir. Toplam 22 hayvan fiziksel özellikleri üzerinden karakterize edilmiştir. Ayı, fil, deve, balina vb. hayvanların vücut irilikleri bir şekilde karakterlerine güç ögesi olarak yansıtılmıştır. Uyku Arkadaşını Arayan Ayı adlı kitapta kendisine istediği cevabı vermeyen tüm hayvanlara sinirlenen ayı, onlara fiziki yapısı sayesinde güç uygulayarak tepki göstermektedir. Şiddet uygulanan hayvanlar arasında inek, balina, aslan ve ördek vardır. Kitapta ayı tüm herkese fiziksel şiddet uygulamaktadır. Ayakları Üşüyen Penguen adlı kitapta da ayı 1sınmak için yanına gelen penguenden istediği cevabı alamadığında yine şiddet göstermiştir. Kitapta bu durum: 'Yok daha neler demiş kutup ayısı sinirle. Teşekkür edeceğine bir de beni mi suçluyorsun? O sinirle kutup ayısı küçük pengueni bir futbol topu gibi havaya firlatmış.' Ş̧eklinde ifade edilmiştir. Ayı ve şiddet birçok kitapta bir arada sunulmuştur. Hatta Ayılar Kitap Okumaz adlı kitapta ayı kasabaya indiği anda tüm insanlar ondan hızla uzaklaşmakta ve korkmaktadır. Geriye kalan hayvanlardan 14'ü estetik ögeler üzerinden tanımlanmıştır. Kuş, tavuk ve karga ötüşü nedeniyle güzel sesli, geveze vb. olarak yansıttlırken, zebra ve uğur böceği farklı renklerinden hareketle karakterize edilmişlerdir. Beş hayvan ise hem fiziksel hem de estetik özellikleriyle vurgulanmıştır. Gergedanın Derisi Neden Buruş Buruş adlı kitapta gergedan 'iri, kaba ve herkese kötü davranan' bir canlı olarak yansıtılmaktadır. Her Şeye Hayır Diyen Aslan adlı kitapta ise aslan diğer hayvanlarından daha güçlü olmasına rağmen bulunduğu sürüyü koruyamadığından 'işe yaramaz ve gereksiz' olarak tanımlanmaktadır. Çevre eğitimi açısından bakıldığında da kitaplarda hiçbir hayvanın bulunduğu habitattaki rolüne dair bilgi elde edilememiştir. Bir başka deyişle hayvanların ekolojik nişine ait herhangi bir çıkarımda bulunulamamıştır.

\section{1 İyi Karakterli Olarak Yansitılan Hayvanlar}

Çocuk kitaplarında yer alan 41 hayvanın tamamı iyi karakter olarak yansıtılmıştır. Bu hayvanların iyi karakterleri ve bu karakterlere yönelik iletilerin bazıları Tablo 4' te sunulmuştur

Tablo 4. Iyi Karakterli Yansitılan Bazı Hayvanlara Yönelik Bulgular

\begin{tabular}{|c|c|c|}
\hline Hayvanlar & $\begin{array}{l}\text { Karakter } \\
\text { Özelliği }\end{array}$ & Özelliği Yansitan İleti \\
\hline Kuş & $\begin{array}{l}\text { Bilgili } \\
\text { Yardımsever }\end{array}$ & $\begin{array}{l}\text { 'Kuş çok bilgilidir ve hayvanların sorunlarına çözüm üretir.' (Bitlenen } \\
\text { Panda, } 1001 \text { Çiçek) }\end{array}$ \\
\hline Karınca & $\begin{array}{l}\text { İyi kalpli } \\
\text { Zeki } \\
\text { Çalışkan }\end{array}$ & $\begin{array}{l}\text { 'Teşekkür ederim iyi kalpli ve akıllı karınca.' (Meraklı Karınca } \\
\text { Cimcim'in Serüvenleri, YKY) } \\
\text { 'Cimcim'in (karınca) ne kadar akıllı ve becerikli olduğunu bilen } \\
\text { uğurböceği'(Meraklı Karınca Cimcim'in Serüvenleri, YKY) } \\
\text { 'Ağustos böceği karıncaya ne kadar da çok çalışıyorsun diye seslenmiş. } \\
\text { Karınca çalışmam gerek demiş soluk soluğa.' (Meraklı Karınca } \\
\text { Cimcim'in Serüvenleri, YKY) }\end{array}$ \\
\hline Tavşan & $\begin{array}{l}\text { Zeki } \\
\text { Cesur }\end{array}$ & $\begin{array}{l}\text { 'Hayvanlar bir sorun yaşadıklarında gidip onu anlatır, tavşanda bir } \\
\text { çözüm yolu bulurmuş'(Bir Gün Tavşan Kralken, YKY) } \\
\text { 'Küçücük salın üzerindeki cesur tavşan nehrin vahşi dalgalarına } \\
\text { meydan okudu'. (Kahraman Olmak İsteyen Tavşan, } 1001 \text { Çiçek) }\end{array}$ \\
\hline Köpek & $\begin{array}{l}\text { Cesur } \\
\text { Sadık } \\
\text { Cana yakın }\end{array}$ & $\begin{array}{l}\text { 'Cesur (Köpeğin adı) onu büyüten ailesine karşı hep sadıktı' (Cesur, } \\
1001 \text { Çiçek) } \\
\text { 'Fificik sokaklarda kendi başına dolaşabilen, cesur bir köpekti' } \\
\text { (Fificik, } 1001 \text { Çiçek) } \\
\text { 'Yavru köpek onu gördüğüne çok sevinmişti. Kuyruğunu heyecanla } \\
\text { sallayıp ona sarıldı.' (Prensesin Köpeği, } 1001 \text { Çiçek) }\end{array}$ \\
\hline
\end{tabular}


çalışkan olarak yansıtılmışlardır. Bu karakter yapısına sahip hayvanlar genel olarak olay örgüsü içerisinde diğer hayvanları sorunlardan kurtarmak için fedakârlık yapan veya zekalarıyla habitatın tamamını tehlikeden kurtaran lider karakterler olarak sunulmaktadır. İletiler incelendiğinde de buna yönelik vurguları içeren çok sayıda cümleyle karşılaşılmaktadır.

\subsection{Hem İyi Hem de Kötü Karakterli Olarak Yansitılan Hayvanlar}

Kitaplarda yer alan 41 farklı türden hayvanın tamamı iyi karakter olarak sunulmuştur. Bununla birlikte bazı hayvanlar hem iyi hem de kötü karakter olarak sunulmuştur. Buna yönelik örnekler Tablo 5'te sunulmuştur.

Tablo 5. Hem İyi Hem de Kötü Karakterli Yansıtılan Bazı Hayvanlara Yönelik Bulgular

\begin{tabular}{|c|c|c|}
\hline Hayvanlar & $\begin{array}{l}\text { Karakter } \\
\text { Özelligi }\end{array}$ & Özelliği Yansitan İleti \\
\hline Ay1 & $\begin{array}{l}\text { Yardımsever } \\
\text { Sinirli } \\
\text { Güçlü }\end{array}$ & $\begin{array}{l}\text { Ateşböcekleri ve arılar dost oldu. Piti de (ayı) onların hep koruyucusu } \\
\text { oldu' (Bal Avcısı Küçük Piti, YKY) } \\
\text { 'O sinirle, kutup ayısı küçük pengueni bir futbol topu gibi havaya } \\
\text { firlatmış.' (Ayakları Üşüyen Penguen, } 1001 \text { Çiçek) } \\
\text { 'Ayılar sinirlendikleri zaman bir köpekbalığından bile daha tehlikeli } \\
\text { olabilirler.' (Uyku Arkadaşı1 Arayan Ay1, } 1001 \text { Çiçek) } \\
\text { 'Piti (ayı) ünlü bir bal avcısıydı firsat buldukça bal çalar. (Bal Avcısı } \\
\text { Küçük Piti, YKY) }\end{array}$ \\
\hline Tilki & $\begin{array}{l}\text { Kurnaz } \\
\text { Bencil } \\
\text { Yardımsever } \\
\end{array}$ & $\begin{array}{l}\text { 'Süper tilki ormandaki tüm hayvanlara yardım etmiş.' (Annesini } \\
\text { Arayan Bukalemun, } 1001 \text { Çiçek) }\end{array}$ \\
\hline Kurt & & $\begin{array}{l}\text { 'Şekeri çok seven kurt üzerine bir koyun postu giymiş ve domuzcuğu } \\
\text { kandırarak şekerlerini almış.' (Şekeri Çok Seven Kurt, } 1001 \text { Çiçek) } \\
\text { 'Sinirlenen kurt dişlerini kuzucuğun postuna geçirmiş.' (Şekeri Çok } \\
\text { Seven Kurt, } 1001 \text { Çiçek) }\end{array}$ \\
\hline Kaplan & Sinsi & 'Kaplan tehlikeli ve sinsidir' (Kaplanı Kandırmak, 1001 Çiçek) \\
\hline Aslan & $\begin{array}{l}\text { Adil } \\
\text { Güçlü } \\
\text { İnatçı }\end{array}$ & $\begin{array}{l}\text { 'Aslan herkesin fikrini dinler'(Neşeli Ormanın Bateristleri, YKY) } \\
\text { 'Sizce de bu aslan sinir bozucu ve inatçı değil mi?' (Her Şeye Hayır } \\
\text { Diyen Aslan, } 1001 \text { Çiçek) } \\
\text { 'Babacığımı seviyorum çünkü: O kocaman ve güçlü' (Sevgili } \\
\text { Babacığım, } 1001 \text { Çiçek) }\end{array}$ \\
\hline Karga & $\begin{array}{l}\text { Geveze } \\
\text { Ak1ll1 }\end{array}$ & $\begin{array}{l}\text { 'Ormanın en geveze hayvan karga yarışmaya katılmış.' (Bir Gün } \\
\text { Tavşan Kralken, YKY) } \\
\text { 'Geveze karga durmadan düşünmeden konuşuyormuş. (Bir Gün } \\
\text { Tavşan Kralken, YKY) } \\
\text { 'Karganın akıllıca planı ile hayvanlar kurtulmuştur.' } \\
\text { (Bir Gün Tavşan Kralken, YKY) }\end{array}$ \\
\hline
\end{tabular}

Tablo 5' te hem iyi hem de kötü karaktere sahip olarak yansıtılan hayvanlardan bazıları yer almaktadır. Buna göre bu karakterde sıklıkla yer alan hayvanlar genel olarak yırtıcılardır. Yırtıcılar dışında fiziksel özellikleri açısından iri hayvanlara da bazı kötü olarak adlandırılabilecek özellikler verilmiştir. $\mathrm{Bu}$ hayvanlarda karşımıza en çok çıkan kötü özellik sinirli olmaları veya güç kullanmalarıdır. Hediyesini İsteyen Fare adlı kitapta fare bir ayı ile karşılaştı̆̆ında 'ayı fareyi kuyruğundan yakalamış, onu havaya kaldırmış ve ters ters bakıp, buzun üzerine bırakmış' şeklinde kurgu oluşturulmuştur. Obur Balina adlı kitabın kahramanı Balina ise tamamen karnı doyurmak için insan avlamayı amaç ediniyor. Kitapta 'Obur balina kocaman kuyruğunu heyecanla sallayarak hedefine yaklaşmış. Kocaman ağzını açmış... daha da açmış... ve sonra... Salın üstünde kürek çeken adamı ve salını tek lokmada yutuvermiş!' şeklinde ifade yer almaktadır. Bununla beraber bu hayvanlara kötü karakteristik özelliklerden daha çok iyi özellikler atfedilmiştir. Yine burada da temel gerekçe bu hayvanların güçlü olmalarından kaynaklı adalet sağlayıcı veya bir sorunu tek başına çözmeleri gibi sempatik beceriler eklendiği tespit edilmiştir. Ancak bu kategorideki hayvanların Tablo 5 'te yer alanları genel olarak fiziksel özellikleri nedeniyle bu şekilde yansıtıldığı düşünülmektedir. 


\section{TARTIŞMA ve SONUÇ}

İncelenen 51 kitapta toplam 41 farklı türde hayvanın yer aldığı sonucuna ulaşılmıştır. Buna göre kitaplarda değinilen hayvan çeşitliliğinin sağlandığı düşünülebilir. Özellikle erken çocukluk döneminde çocuklar kedi, köpek, kuş ve bazı böcek türleri dışında farklı hayvanlarla gündelik yaşamlarında karşılaşmazlar. Birçoğumuz vahşi veya endemik hayvanları genellikle TV'de, dergilerde veya internette görmekteyiz (Prokop, Prokop, Tunnicliffe ve Diran, 2007). Çocuklarda tıpkı yetişkinler gibi farklı tür hayvanları bu kaynaklardan tanımakta, bunlara ek olarak hayvan modelli pelüş oyuncaklar aracılığıyla etkileşime girmektedir (Tunnicliffe, Gatt, Agius ve Pizzuto, 2008). Ancak Prokop vd., (2007) özellikle erken çocukluk döneminde bu tarz ikincil kaynaklardan edinilen biyolojik kavramlarda yanlış öğrenmelerin ve kavram yanılgılarının oluştuğuna vurgu yapmaktadır. Bu noktada çocuklara doğru ve gelişimine uygun düzeydeki bilgiyi kitaplardan edinmesi önem kazanmaktadır. Kitaplarda yer alan hayvanların çeşitliliği ve onlar hakkında verilecek olan doğru bilgiyle çocukların hayvanlara dair bilgi düzeyinin artması sağlanabilir. Kağıtçıbaşı (2010) yeterli bilgi düzeyine sahip olunmadan herhangi bir kavrama yönelik tutum geliştirmenin güçlügüne değinir. Bu nedenle kitaplarda yer alan hayvan sayısının çok olması tek başına bir şey ifade etmese de, çocukların farklı türden hayvanları en azından ikincil bir kaynaktan tanımalarına olanak tanıyacaktır. Tablo 1.'de de görüldüğü gibi kitaplarda çocukların gündelik yaşamda karşılaşma ihtimalleri düşük olan pek çok yırtıcı, sürüngen veya eklem bacaklı hayvanın olması bu açıdan önemlidir.

Bununla birlikte kitaplarda yer alan 41 hayvanın tamamı "iyi” karakter özellikleri göstermektedir. Bu özellikler arasında özellikle öne çıkanlar; yardımseverlik, çalışkan olma ve adil olmadır. Bununla beraber toplam 10 hayvana "iyi" özellikler dışında bazı kitaplarda "kötü" karakter özellikleri de verilmiştir (bknz. Tablo I). Genel olarak bu hayvanların yırtıcılar sınıfında oldukları veya gergedan ve yılan gibi estetik açıdan göze hoş görünmeyen hayvanlar oldukları görülmektedir. Biyolojik ve ekolojik kavramlara yönelik bilgilerimizi okula başlamadan çok önce ediniriz (Teixeria, 2000). Burada en önemli bilgi kaynă̆ını kitaplar oluşturmaktadır. Çardak (2009) çocukların doğal alanlardan uzak yaşamalarının bir sonucu olarak dergi, kitap, TV ve İnternet üzerinden hayvanların fiziksel ve estetik özelliklerine dair bilgi edindiklerini, bunun da hayvan hakkında yetersiz bilgiye yol açtığını vurgulamaktadır. Buna ek olarak birde özellikle bazı hayvanlara ithaf edilen ve onları "kötü" gösteren özellikler eklenince bu seferde çok erken yaşta belirli hayvanlara karşı korku ve olumsuz tutum sergilenmeye başlanmaktadır. Çardak (2009)'ın yaptığı araştırmada çocukların çok tehlikeli ve tehlikeli olarak sınıfladıkları hayvanlar arasında en başta yılan, kurt, aslan, ayı ve kaplan gelmektedir. Borgi ve Cirulli (2015)'nin araştırmasında da çocuklar en çok yılan, ayı, köpekbalığından korkarken; tavşan, at ve kelebek genel olarak sevilen hayvanlar olarak belirtilmiştir. Almeida, Vasconcelos ve Strecht-Ribeiro (2014)' un araştırması da çocukların en çok korktukları hayvanların yırtıcılar olduğunu vurgulamaktadır. Tüm bu araştırmalardaki korkulan hayvanlar Tablo 1.'den de anlaşılacağı üzere kitaplarda "kötü" karakter rollerine sahip olan hayvanlardır. Elde edilen bu sonuç bile aslında bu durumun tesadüf olmayacağının bir kanıtı gibidir. Yine Prokop ve Kubiatko (2008)' nun yaptıkları araştırmada çocukların özellikle avcı konumundaki yırtıcılara karşı olumsuz bir bakış açısına sahip oldukları tespit edilmiştir. Bu araştırma kapsamında incelenen kitaplarda "kötü" karakter özelliği gösteren hayvanların önemli bir bölümü yırtıcıdır. Söz konusu araştırmacılar yaş büyüdükçe yırtıcılara olan olumsuz tutumun da arttığını belirtmektedir. Bjerke, Kaltenborn ve Ødegårdstuen (2001) ise vahşi yaşamın anlaşılmasının çocukta çok daha yoğun bir ekolojik bilgin ve hayatı anlamlandırma becerisi kazandırdığını belirtmektedirler. Buna göre çocukların eğitimi için önemli olan vahşi yaşam veya yırtıcıların doğru bir şekilde sunulmasıdır. Almeida, Vasconcelos ve Strecht-Ribeiro (2014) hayvanlar hakkında elde edilen doğru bilginin onları sevmeyi ve sevmenin de onları korumayı kolaylaştırdığını belirtmektedir.

Kitaplarda yer alan hayvanların çok önemli bir bölümüne fiziksel özellikleri temel alınarak çeşitli roller dağıtılmıştır. Özellikle ayı, zürafa, deve, aslan, kaplan gibi hayvanlar fiziksel olarak bedenlerinin büyüklügü nedeniyle "iyi” karaktere bürünürken de güç odaklı tanımlamalar yapılarak, lider rolleri verilmiştir. Bu hayvanlar genelde sorun çözen ve sorumluluk alan hayvanlar olarak sunulmuştur. Ancak yine bu hayvanlara "kötü" roller de biçilmiş ve yine fiziksel; yılan ve aslana ise hem fiziksel hem de estetik özelliklerden hareketle roller verilmiştir. Kubiatko (2012) yaptığı araştırmada fiziksel görünüşleri ve estetik algılarından dolayı ayı, 
maymun, yılan ve köpekbalığının çocuklar tarafından "korkutucu" olarak tanımlandıklarını tespit etmiştir. Tablo I ve Tablo II incelendiğinde "kötü" karakter özelliği gösteren hayvanların fiziksel ve estetik özelliklerine de vurgu yapıldığı görülmektedir. Örneğin Gergedanın Derisi Neden Buruş Buruş adlı kitapta gergedanın estetik açıdan çirkinliği ve onun sinirli bir canlı olması vurgusu yapılmaktadır. Özellikle Kubiatko (2012)'nun araştırmasında çocuklar tarafindan korkutucu olarak gösterilen hayvanlar kitaplara da iyi roller aldıkları gibi kötü roller de almıştır. Williams (2014) ve Horsman (2014) çocuk kitaplarında yer alan hayvan karakterlerin kültür içerisinde belirli kimlik rollerini tespit ettiklerini ve kötü karaktere sahip bir hayvanın çocuklar tarafından gerçek yaşamda da kötü olarak algılanmasının önünü açtığını vurgularlar. Çocukların hayvanlara karşı istendik davranış sergileyebilmeleri için hayvan hakkında verilen bilgilerin ekoloji temelli ve doğru olması gerekmektedir (Hawkins ve Williams, 2016).

Ekolojik açıdan doğada hiçbir canlı kötü ve zararlı değildir. İnsan-merkezli bir anlayışla düşünüldüğünde bazı hayvanlar insan yaşamı için tehlike oluşturduğundan kötü veya "vahşi" olarak algılanmaktadırlar. Bu algının oluşmasında belki ikincil düzeyde bir etkisi de olsa kitaplar da sorumludur. Piaget (1970) bilginin inşasında var olan bilgilerin önemine dikkat çeker. Erken çocukluk dönemindeki bir çocuk ilk eğitimini aile içerisinde alacak, kitap, dergi, oyuncak, internet ve televizyon aracıllı̆̆ıla da bilgiye ulaşacaktır. Özellikle kitaplar çocuklar için önemli eğitim araçlarıdır. Hayvan karakterlerin yer aldığı kitaplar çocuklar tarafından oldukça sevilen kitaplardır (Bedford, 2012). Hawkins ve Williams (2016) çocukların hayvan sevgisinin altında yatan psikolojik faktörleri araştırdığı araştırmalarında hayvanlara yönelik deneyimin ve bilginin fazla olmasının çocukta hayvanlara karşı olumlu tutum gelişmesini hızlandırdığını tespit etmiş̧lerdir. Tripper (2011) hayvanlara doğrudan deneyim sağlanamadığı zamanlarda kitapların bu boşluğu kapatmada önemli olduklarını ancak doğru bir çıkarım için çocuk kitaplarındaki hayvanların duygusallıktan uzak değerlendirilmeleri gerektiğini vurgulamaktadır. Ayrıca çocukların hayvanların biyosferdeki görevlerini anladıklarında onlarla insan yaşamı arasında bağ kurabilir ve bu bağda hayvanlara karşı olumlu bakış açısı kurmayı desteklemektedir (Muldoon, Williams ve Lawrence, 2016).

Elde edilen sonuçlar ve yapılan tartışma sonucunda öncelikle çocuk kitaplarının çevre eğitimi açısından sadece hayvan değil, bitki ve insan boyutları açısından da incelenmesinin alana katk1 sağlayacağı düşünülmektedir. Hayvanları konu edinen kitapların içeriği, olay örgüsü ve hayvanların okuyucuya yansıtılma şekli alan uzmanları tarafından kontrol edilirse erken yaşlarda geliştirilebilecek olumsuz tutumların önleneceğine inanılmaktadır. Özellikle eğitim ortamlarında kullanılan kitapların hayvanlar açısından doğru mesaj taşımalarının üstünde durulmalıdır. Ailelerin de çocukları için seçtikleri kitapların içeriklerini derinlemesine inceleyerek, doğru yazılmış kitaplar için daha ısrarcı olmaları gerektiğine, bu sayede yayınevlerinin de yayın kataloglarındaki ürünlerin içerik kalitesine daha dikkatli yaklaşacaklarına inanılmaktadır. Ayrıca bu araştırmanın belirli bir bölümünde de savunulan ve alanyazın tarafından desteklenen kitaplardaki olumsuz ifadelerin çocukların hayvanlara yönelik tutumunu nasıl etkilediği psikolojik temelli araştırmalarla daha derinlemesine incelenmelidir. Söz konusu araştırmada sadece iki yayınevinden çalışma grubu oluşturmuştur. Bu araştırmanın sınırlı kaldığı noktadır. Çalışma grubunun genişletilmesi, hatta yayınevlerinin kitapları basımına karar vermesi gibi süreçler nitel temelli çalışılabilir. 


\section{KAYNAKLAR}

Ahi, B. (2016). Flying, feathery and beaked objects: Children's mental models about bird. International Electronic Journal of Environmental Education, 6(1), 1- 16.

Almeida, A. Vasconcelos, C. \& Strecht-Ribeiro, O. (2014). Attitides toward animals: A study of portuguese children. Anthrozoös, 27(2): 173-190.

Bedford, A., W. (2012). Children's books: Animal antics. Childhood Education, 88(3), 195-198.

Bjerke, B., Kaltenborn, B., P. \& Ødegårdstuen, T., S. (2001). Animal-Related activities and appreciation of animals among children and adolescents. Anthrozoös, 14(2), 86-94.

Borgi, M. \& Cirulli, F. (2015). Attitudes toward animals among kindergarten children: Species preferences. Anthrozoös, 28(1): 45-59.

Çardak, O. (2009). Students' ideas about dangerous animals. Asia-Pacific on Science Learning and Teaching, 10(2), 1-15.

Çeçen, M. ve Akaydın, Ş. (2015). Okuma becerisiyle ile ilgili makaleler üzerine bir içerik analizi. Eğitim ve Bilim (40), 183-193.

Derman, A. \& Aslan, Z. (2016). Çevre eğitimi için kültürel bir bakış açısı: Dede Korkut Hikâyeleri. Turkish Studies, 11(14), 201-220.

Falkingham, L.T. ve Reeves, R. (1998). Context analysis- a technique for analysing research in a field, applied to literature on the management of R and D at the section level. Scientometrics, 42(2), 97-120.

Hawkins, R., D. \& Williams, J., M. (2016). Children's beliefs about animal minds (Child-BAM): Associations with positive and negative child-animal interactions. Anthrozoös 29(3), 503-519.

Hazır-Bıkmaz, F., Aksoy, E., Tatar, Ö. ve atak Altınyüzük, C. (2013). Eğitim programları ve öğretim alanında yapılan doktora tezlerine ait içerik çözümlemesi (1974-2009). Eğitim ve Bilim, 38(168), 1300-1337.

Horsman, Y. (2014). Infancy of art: Comics, childhood and picture books. Journal of Graphic Novels and Comics, $5(3), 323-335$.

Kağıtçıbaşı, Ç. (2010). Günümüzde insan ve insanlar. (12. Basım). İstanbul: Evren.

Kubiatko, M. (2012). Kindergarten children's perception of animals focusing on the look and fear of animals. Educational Science: Theory \& Practice, Special Issue, 3181-3186.

McCrindle, C., M., E. \& Odendaal, J., S., J. (1994). Animals in books used for preschool children. Anthrozoös, $7(2), 135-1$.

Muldoon, J., C., Williams J., M. \& Lawrence, A. (2016). Exploring children's perspectives on the welfare needs of pet animals. Anthrozoös, 29(3), 357-375.

Özden, M. ve Durdu, L. (2016). Ĕgitimde üretim tabanlı çalışmalar için nitel araştırma yöntemleri. Ankara: Anı Yayınc1lik.

Pallant, J. (2011). SPSS survival manual. (4th Edition). Sydney: Allen \& Unwin.

Patton, M., C. (2014). Nitel araştırma ve değerlendirme yöntemleri. (Çev. Ed. M. Bütün \& S. B. Demir). Ankara: Pegem.

Peat, J. (2001). Health science research: A handbook of quantitative methods. Sydney: Allen \& Unwin.

Piaget, J. (1970). Genetic epistemology. New York: The Norton Library.

Prokop, P., Prokop, M., Tunnicliffe, D., S. \& Diran, C. (2007). Children's ideas of animals' internal structures. Journal of Biological Education, 41(2), 62-67.

Roxburgh, S., Zolotow, C., L'Engle, M. \& Kruse, G., M. (1982). Defining a good children's book. Theory Into Practice. 21(4), 262-267.

Şahin, G. (2014). Pictures as a visual stimulus in preschool children's books. International Periodical For The Languages, Literature and History of Turkish or Turkic, 9(3), 1309-1324.

Teixeira, F. (2000). What happens to the food we eat? Children's conceptions of the structure and function of the digestive system. International Journal of Science Education, 22, 507-520.

Tipper, B. (2011). A dog who I know quite well': Everyday relationships between children and animals. Children's Geographies. 9(2), 145-165.

Tunnicliffe, S. D., Gatt, S., Agius, C., \& Pizzuto, S. A. (2008). Animals in the lives of young Maltese children. Eurasia Journal of Mathematics, Science \& Technology, 4(3), 215-221.

Uğurlu, S. (2013). Resimli çocuk kitaplarında hayvan karakteri kullanımı. International Periodical For The Languages, Literature and History of Turkish or Turkic Volume 8(4), 1381-1393. 
Williams, S., J. (2014). Fireflies, frogs, and geckoes: Animal characters and cultural identity in emergent children's literature. New Review of Children's Literature and Librarianship, 20(2), 100-111.

Yazıcı Okuyan, H. \& Gedikoğlu. Y. G. (2012). Aytül Akal'ın çocuk kitaplarında çevre bilinci ve duyarlığı." Turkish Studies, 7(2), 793-806.

Yılmaz, O. (2016). Kurgusal nitelikli çocuk kitapları ve karakter eğitimi. Ana Dili Eğitimi Dergisi, 4(3), 311-325. 